\title{
Validation of a short questionnaire in English and French for use in patients with persistent upper gastrointestinal symptoms despite proton pump inhibitor therapy: The PASS (Proton pump inhibitor Acid Suppression Symptom) test
}

\author{
David Armstrong MA MB BChir FRCPUK FRCPC ${ }^{1}$, Sander JO Veldhuyzen van Zanten MD PhD ${ }^{2}$ \\ Sharon A Chung $\mathrm{PhD}^{3}$, Colin M Shapiro MBBCh PhD FRCPC ${ }^{3}$, Sukhjeet Dhillon BSc ${ }^{4}$, Sergio Escobedo MSc ${ }^{5}$, \\ Bijan K Chakraborty MStat ${ }^{5}$, Vijay Mann $\mathrm{MSc}^{5}$, Lisa Tanser $\mathrm{MSc}^{5}$, Krista Nevin BScHons ${ }^{5}$
}

D Armstrong, SJO Veldhuyzen van Zanten, SA Chung, et al. Validation of a short questionnaire in English and French for use in patients with persistent upper gastrointestinal symptoms despite proton pump inhibitor therapy: The PASS (Proton pump inhibitor Acid Suppression Symptom) test. Can J Gastroenterol 2005;19(6):350-358.

BACKGROUND: The management of persistent symptoms during acid suppression therapy in patients with gastroesophageal reflux disease or dyspepsia might be improved if patient-physician communication regarding the presence and character of these persistent symptoms were facilitated.

AIM: To validate a short, simple questionnaire (the Proton pump inhibitor [PPI] Acid Suppression Symptom [PASS] test), in English and French, to identify patients with persistent acid-related symptoms during PPI therapy and document their response to a change in therapy.

METHODS: Patients with persistent acid-related symptoms on PPI therapy were interviewed to produce a draft, five-item questionnaire; content validity was evaluated by focus groups comprising Englishand French-speaking patients. Psychometric validity was subsequently evaluated in a multicentre, family practice-based study of Englishand French-speaking patients with persistent acid-related upper gastrointestinal symptoms despite PPI therapy. The PASS test, Global Overall Symptom scale, Gastrointestinal Symptom Rating Scale (GSRS), Quality of Life in Reflux and Dyspepsia questionnaire and Reflux Disease Questionnaire were completed at baseline and repeated after one week while patients continued their original PPI therapy. All patients then received esomeprazole $40 \mathrm{mg}$ once daily for four weeks, after which all questionnaires and an evaluation of overall treatment effect were completed.

RESULTS: Content validity was established in 20 English- and 16 French-speaking patients. Psychometric validation in 158 Englishand 113 French-speaking patients revealed good-to-excellent testretest reliability coefficients: 0.76 for English; 0.68 for French. For construct validity, the PASS test showed moderate-to-high correlation with the GSRS scale ( 0.51 for English; 0.43 for French). After four weeks of therapy, the PASS test score fell to zero in $30 \%$ of English- and 33\% of French-speaking patients, while the Global
Overall Symptom score fell to one (no symptoms) in 32\% of patients (English- and French-speaking); the PASS test demonstrated good responsiveness in comparison with the GSRS, Reflux Disease Questionnaire and Quality of Life in Reflux and Dyspepsia questionnaire.

CONCLUSION: The five-item PASS test is a valid tool for the evaluation of persistent acid-related symptoms in patients receiving PPI therapy. It demonstrates good content validity, test-retest reliability, responsiveness and construct validity in both English and French forms. The PASS test is a simple, clinically applicable tool for the identification of patients with persistent acid-related symptoms during therapy and the assessment of their responses to a change in therapy.

Key Words: Dyspepsia; Health-related quality of life; Heartburn; Proton pump inhibitor

\section{Validation d'un bref questionnaire en langue} anglaise et en langue française à l'intention de patients qui souffrent de symptômes des voies digestives hautes persistants malgré un traitement par inhibiteurs de la pompe à protons : Le test PASS (pour Proton pump inhibitor Acid Suppression Symptom)

\footnotetext{
HISTORIQUE : La prise en charge des symptômes persistants malgré un traitement par suppression acide chez les patients qui souffrent de reflux gastro-œsophagien et de dyspepsie pourrait être améliorée si l'on facilitait la communication médecin-patient sur ces symptômes persistants et leur nature.

OBJECTIF : Valider un questionnaire bref et simple (le questionnaire PASS pour Proton pump inhibitor [PPI] Acid Suppression Symptom test) en anglais et en français de manière à identifier les patients qui souffrent de symptômes persistants liés à l'acidité durant leur traitement par IPP et documenter leur réponse à un changement de traitement.

MÉTHODE : Des patients qui souffrent de symptômes persistants liés à l'acidité alors qu'ils se trouvaient sous IPP ont été interrogés afin de produire l'ébauche d'un questionnaire à cinq éléments. La validité du contenu
}

${ }^{1}$ Division of Gastroenterology, McMaster University, Hamilton, Ontario; ${ }^{2}$ Division of Gastroenterology, Dalhousie University, Halifax,

Nova Scotia; ${ }^{3}$ Department of Psychiatry, University Health Network, Toronto; ${ }^{4}$ School of Optometry, University of Waterloo, Waterloo;

${ }^{5}$ AstraZeneca Canada Inc, Mississauga, Ontario

Correspondence: Dr David Armstrong, Division of Gastroenterology, HSC-4W8, McMaster University Medical Centre, 1200 Main Street West,

Hamilton, Ontario L8N 325. Telephone 905-521-2100 ext 76404, fax 905-521-4958, e-mail armstro@mcmaster.ca

Received for publication November 9, 2004. Accepted March 14, 2005 
a été évaluée par des groupes composés de patients de langue anglaise et de langue française. La validité psychométrique a, par la suite, été évaluée dans le cadre d'une étude multicentrique auprès de cliniques de médecine familiale, chez des patients de langue anglaise et française souffrant de symptômes digestifs persistants liés à l'acidité en dépit d'un traitement par IPP. Le test PASS, une échelle globale d'évaluation des symptômes, l'échelle GSRS (pour Gastrointestinal Symptom Rating Scale) et un questionnaire sur la qualité de vie en présence de RGO et de dyspepsie et le questionnaire sur le RGO ont été complétés au départ, puis après une semaine, alors que les patients maintenaient leur traitement original par IPP. Tous les patients ont alors reçu $40 \mathrm{mg}$ d'ésoméprazole, une fois par jour, pendant quatre semaines, après quoi tous les questionnaires et une évaluation de l'effet global du traitement ont été repris.

RÉSULTATS : La validité du contenu a été établie avec la collaboration de 20 patients de langue anglaise et de 16 patients de langue française. La validation psychométrique chez 158 patients de langue anglaise et 113 patients de langue française a révélé des coefficients de fiabilité testretest de bons à excellents : 0,76 dans le cas de l'anglais, 0,68, dans le cas du français. Pour ce qui est de la validité conceptuelle, le test PASS a montré une corrélation de modérée à élevée avec l'échelle GSRS (0,51 pour l'anglais, 0,43 pour le français). Après quatre semaines de traitement, le score au test PASS est tombé à 0 chez $30 \%$ des patients de langue anglaise et $33 \%$ des patients de langue française, alors que le score à l'évaluation globale des symptômes est tombé à 1 (aucun symptôme) chez 32 \% des patients (de langues anglaise et française). Le test PASS a démontré un bon degré de réactivité en comparaison avec le GSRS, le questionnaire sur le RGO et le questionnaire sur la qualité de vie en présence de RGO et de dyspepsie.

CONCLUSION : Le test PASS à cinq éléments est un outil valide pour l'évaluation des symptômes persistants liés à l'acidité chez les patients sous IPP. Il fait état de résultats favorables pour ce qui est de la validité du contenu, de la fiabilité test-retest, de la réactivité et de la validité conceptuelle, tant en anglais qu'en français. Le test PASS est un outil simple et facile à appliquer en clinique, pour l'identification des patients qui souffrent de symptômes persistants liés à l'acidité alors qu'ils sont sous traitement et pour l'évaluation de leur réponse au changement de traitement.

Although there are validated research questionnaires for assessing upper GI symptoms and their response to therapy $(22,23)$, no questionnaire has been designed specifically for clinical practice to identify patients who have persistent symptoms during therapy and to determine whether these symptoms might respond to more effective acid suppression therapy. The aim of the present study was to develop and validate a brief, user-friendly questionnaire that could be used by patients receiving PPI therapy to report the extent of severity of any persistent upper GI symptoms. The present paper describes the development and validation of the PPI Acid Suppression Symptom (PASS) test, in English and Canadian French, in a primary care setting.

\section{METHODS}

A literature review did not identify an appropriate, validated clinical assessment tool for use in patients receiving standard PPI therapy.

recurrent symptoms once they discontinue therapy $(5,15)$ and many patients have persistent symptoms despite continued therapy. Indeed, $15 \%$ to $20 \%$ of patients receiving PPI therapy are taking double-dose therapy (16). Although this may be unnecessary in some patients, it may also indicate that many patients still experience persistent acid-related symptoms during standard, once-daily PPI therapy. Gastroesophageal reflux disease (GERD) symptoms are associated with a decreased quality of life (17-19) if they are mild and occur on two or more days per week or if they are moderate and occur at least once a week. Furthermore, GERD symptoms are often sufficiently severe to interfere with work and daily activities; in one study (15), up to $50 \%$ of patients took over-the-counter medications in addition to their prescribed therapy. Thus, effective symptom control has the potential to produce a significant improvement in quality of life for many patients.

The extent to which patients experience persistent GERD symptoms during therapy is not generally appreciated by physicians, who may tend to overestimate the success of PPI therapy $(20,21)$. As a result, physicians may not elicit, and patients may not report, persistent upper GI symptoms during therapy (20). The management of persistent symptoms in patients taking PPIs might, therefore, be facilitated if there was a standardized, validated tool that could be used to identify patients who still had symptoms and to determine whether these symptoms might respond to a change in acid suppression therapy.

\section{Identification of relevant symptoms}

A telephone survey was conducted, by a third party, to identify the nature and severity of persistent symptoms in patients receiving PPIs. Respondents were selected from a list of adults taking PPIs who had indicated their willingness to participate in market research. Respondents with persistent symptoms despite continued PPI therapy were invited to complete the survey, which was comprised of a structured series of questions to identify each individual's symptoms before the start of therapy, current symptoms, quality of life, preferences and interactions with physicians.

The results of this survey were then summarized and reviewed by a panel of 11 physicians, including gastroenterologists and family physicians, as the basis for developing a short questionnaire that could be used to evaluate persistent symptoms during ongoing PPI therapy.

\section{Construction of initial short questionnaire (PASS test)}

Based on the telephone survey, it was determined that there were five major areas of concern with respect to patients' symptoms; each major area was, therefore, addressed with one question (Table 1). The draft PASS test, developed in French and English forms, had five closed 'Yes/No' questions designed to address the presence and impact of upper GI symptoms. The first question asked about the presence or absence of symptoms and the other four questions dealt with specific details. 
TABLE 1

Mean 'Yes' response rates (English [E], French [F]) to five issues related to the use of the Proton pump inhibitor Acid Suppression Symptom (PASS) scale*. PASS content validation questionnaire

\begin{tabular}{|c|c|c|c|c|c|c|c|c|c|c|c|c|}
\hline \multirow[b]{2}{*}{ PASS question } & \multicolumn{2}{|c|}{$\begin{array}{c}\text { Percentage } \\
\text { answering Yes }\end{array}$} & \multicolumn{2}{|c|}{$\begin{array}{l}\text { Is the question } \\
\text { clear and easy } \\
\text { to understand? }\end{array}$} & \multicolumn{2}{|c|}{$\begin{array}{l}\text { Is the question } \\
\text { vague and } \\
\text { confusing? }\end{array}$} & \multicolumn{2}{|c|}{$\begin{array}{l}\text { Is the question } \\
\text { related to your } \\
\text { experience? }\end{array}$} & \multicolumn{2}{|c|}{$\begin{array}{c}\text { Is this an } \\
\text { important } \\
\text { complaint? }\end{array}$} & \multicolumn{2}{|c|}{$\begin{array}{l}\text { Do you like } \\
\text { the wording? }\end{array}$} \\
\hline & $\mathbf{E}$ & $\mathbf{F}$ & E & $\mathbf{F}$ & E & $\mathbf{F}$ & E & $\mathbf{F}$ & E & $\mathbf{F}$ & E & $\mathbf{F}$ \\
\hline $\begin{array}{l}\text { 2. Supplemental } \\
\text { medications }\end{array}$ & 65 & 67 & 6.5 & 6.2 & 2.2 & 1.8 & 5.3 & 6.0 & 5.6 & 5.8 & 5.7 & 6.4 \\
\hline 3. Sleep affected & 80 & 42 & 6.4 & 6.7 & 2.3 & 1.1 & 5.7 & 6.0 & 5.9 & 5.8 & 5.9 & 6.7 \\
\hline 5. Daily activities & 50 & 25 & 6.4 & 7.0 & 2.1 & 1.8 & 5.3 & 5.8 & 5.8 & 5.8 & 6.0 & 6.3 \\
\hline
\end{tabular}

*Scores on seven-point Likert scale items anchored at each end; 1 = completely disagree; 7 = completely agree

\begin{tabular}{|c|c|}
\hline $\begin{array}{l}\text { PASS TEST } \\
\text { Are you taking prescription medication for any of the following stomach } \\
\text { problems/symptoms: } \\
\text { - Stomach pain or discomfort } \\
\text { - Heartburn (a burning feeling rising from your stomach or lower chest towards } \\
\text { your neck or burning feeling located behind the breastbone which may or may } \\
\text { not rise in the chest) } \\
\text { - Sour taste in mouth/acid regurgitation (feeling of regurgitation or unpleasant } \\
\text { feeling moving upwards to the mouth) } \\
\text { - Excessive burping/belching (passing of gas through the mouth) } \\
\text { - Increased abdominal bloating (feeling of abdominal distension or fullness) } \\
\text { - Nausea (the sensation of needing to vomit) }\end{array}$ & $\begin{array}{l}\text { TEST PASS } \\
\text { Prenez-vous un médicament sur ordonnance pour vos problèmes d'estomac? } \\
\text { OU } \\
\text { Prenez-vous un médicament sur ordonnance pour l'un des problèmes (d'estomac) suivants : } \\
\text { - Douleur/malaise à l'estomac } \\
\text { - Brûlures d'estomac (sensation de brûlure remontant de l'estomac ou du bas de la } \\
\text { poitrine vers le cou ou sensation de brûlure derrière le sternum qui remonte ou ne } \\
\text { remonte pas vers la poitrine) } \\
\text { - Goût sur dans la bouche/régurgitations acides (sensation de régurgitation ou } \\
\text { sensation désagréable d'un retour d'aliments dans la bouche) } \\
\text { - Éructations/rôts excessifs (émission par la bouche de gaz provenant de l'estomac) } \\
\text { - Ballonnement abdominal accru (sensation de distension abdominale ou de } \\
\text { plénitude gastrique) } \\
\text { - Nausées (envie de vomir) } \\
\text { - Satiété précoce - sensation que l'estomac est rempli peu après avoir commencé de } \\
\text { manger ou impossibilité de terminer les repas - sensation de digestion anormale ou } \\
\text { lente) }\end{array}$ \\
\hline
\end{tabular}

Figure 1) The Proton pump inhibitor Acid Suppression Symptom (PASS) test in English and French

The draft test was validated in two stages with two separate study groups; the first assessed content validity and the second assessed psychometric validity.

\section{Content validity}

Content validity was evaluated in English- and French-speaking adults taking PPIs who had indicated their willingness to participate in market research and who were reimbursed for their time. An independent ethics committee (Institutional Review Board Services, Aurora, Ontario) approved the evaluation procedure.

In addition to the draft PASS test, patients completed a content validation questionnaire to evaluate the content of the questions and assess whether the wording was clear, unambiguous and relevant to their own experience. The PASS test format was finalized based on an analysis of the content validity questionnaire results (Figure 1).

Psychometric validity

Psychometric validation of the PASS test was performed in a three-visit multicentre study at 38 family practice centres across Canada to evaluate 'test-retest' reliability, construct validity and responsiveness. The study protocol was approved by an independent ethics committee (Institutional Review Board Services, Aurora, Ontario); informed written consent was obtained from each patient. 
Patients were eligible to participate in the study if they were 18 years of age or older, spoke English or French as a first language, had persistent GI symptoms (including epigastric pain or discomfort, heartburn, acid regurgitation, excessive burping or belching, abdominal bloating, a feeling of abnormal or slow digestion, early satiety and nausea) and had been taking one of the following PPIs at standard once-daily doses for at least the previous eight weeks: omeprazole $20 \mathrm{mg}$; rabeprazole $20 \mathrm{mg}$; lansoprazole $30 \mathrm{mg}$; or pantoprazole $40 \mathrm{mg}$. Major exclusion criteria included current use of esomeprazole, documented upper GI surgery such as gastric resection, vagotomy, pyloroplasty, hiatus hernia surgery or fundoplication, and the presence of any alarm symptoms requiring investigations.

A history and physical examination were performed in all patients and baseline demographic data were recorded. Adverse events and the use of concomitant medications were recorded throughout the study. PPI use during the week before entry into the study was documented. Patients then completed the PASS test and the Global Overall Symptom (GOS) scale to document the severity of their upper GI symptoms over the previous two days. To demonstrate test-retest reliability of the PASS test, patients were asked to continue their baseline medication for one week (up to 14 days maximum) before they returned to the clinic, at which time they again completed the PASS test, the GOS scale, the Gastrointestinal Symptom Rating Scale (GSRS), the Overall Treatment Evaluation (OTE), the Quality of Life in Reflux and Dyspepsia (QoLRAD) questionnaire and the Reflux Disease Questionnaire (RDQ). Patients were eligible to continue in the study only if they had reported upper GI symptoms of at least mild severity (GOS score of 3 or more) during the last two days before their second visit (24).

Laboratory measurements, including a urine pregnancy test if applicable, were performed at the second visit. All patients then received open label treatment with esomeprazole $40 \mathrm{mg}$ taken each morning, $30 \mathrm{~min}$ before breakfast, for the next four weeks. Esomeprazole was chosen because of its superiority, at standard dose, to other PPIs at increasing gastric $\mathrm{pH}$ and producing symptom relief for patients with erosive eosphagitis $(25,26)$. The patients discontinued other PPIs at this visit but were allowed to continue other medications.

After four weeks, patients returned to the clinic for the third and final visit, at which time all questionnaires administered at the second visit were repeated and compliance was assessed by pill count of returned medication.

The PASS test was evaluated with respect to patients' responses to the individual questions and with respect to the total sum score (minimum score 0: patient has no symptoms; maximum score 5: patient has symptoms requiring supplemental medications and affecting sleep, eating, drinking and daily activities).

The GOS is a seven-point Likert scale, scored from 1 (no problem) to 7 (very severe problem), that measures the overall severity of dyspepsia symptoms (24).

The GSRS includes 15 questions that address GI symptoms in five different domains: reflux, abdominal pain, indigestion, diarrhea and constipation. The GSRS questions are answered using a seven-point Likert-like scale, scored from 1 (no symptoms) to 7 (very severe symptoms) (27,28).

The QoLRAD questionnaire consists of 25 questions in five dimensions (emotions; sleep; vitality; food and drinking habits; and physical and social functioning) that assess the impact of upper GI symptoms on patient quality of life and daily functioning. This questionnaire is a seven-point Likert-like scale, scored from 1 (severe impact) to 7 (no impact) for each domain. Scores are reported for each domain and overall (29).

The RDQ is a self-administered questionnaire used to measure the frequency and severity of certain patient symptoms: heartburn, regurgitation, epigastric pain, and overall symptoms, over the previous four weeks. Symptom frequency is ranked according to six choices (did not have; less than one day a week; one day a week; two to three days a week; four to six days a week; and daily) as is severity (did not have; very mild; mild; moderate; moderately severe; severe) (30).

The OTE is a 15-point scale that measures the magnitude of change in health status ( -7 to -1 is worse; 0 is no change; and 1 to 7 is better). Subjects were first asked to report their symptoms as improved, about the same, or worse when compared with the previous visit. If changed, patients had to indicate the magnitude of change on seven-point scales ( 1 to 7 or -1 to -7 ). Patients were then asked to indicate how important the change (if it occurred) was to them on another seven-point scale (31).

\section{Test-retest reliability}

Generalizability analysis (G-analysis [32]) was conducted to account for three clearly defined sources of variation that were identified in the present study: assessments at two time points; five test items; and subject characteristics. Intraclass correlation coefficients, representing the ratios of true variance to total variance, were calculated using a repeated measures model to account for the sources of variation. Mean squares from the within-subjects effects were extracted for each of the following - subject*time, subject*item and subject*time*item (error) - to calculate the variances and, consequently, the $G$ coefficients for test-retest reliability and internal consistency (alpha) for the PASS test. The strength of the relationship between each PASS question and the total PASS score was assessed by the total-to-item correlation.

For PASS inter-item analysis, individual phi correlation coefficients were calculated. Correlations were considered low-to-moderate if the coefficients fell between 0.4 and 0.6 ; moderate-to-high if greater than 0.6; and excellent if greater than 0.8.

\section{Construct validity}

Construct validity refers to how well the patient's status is reflected by the PASS test compared with other standard questionnaires. It is determined by the degree of correlation (Spearman's rank correlation $\rho$ ) between scores on the PASS scale and those on three other validated scales: GSRS, QoLRAD and RDQ.

\section{Responsiveness and discriminant power}

Responsiveness to changes in patients' symptoms due to treatment was evaluated by the use of 'effect size' and symptom improvement. The effect size reflects changes in symptoms standardized by the variability of the change (33). It is calculated using the change in score from pretreatment (visit 2) to four weeks of treatment (visit 3), divided by the baseline SD. Effect sizes between 0.4 and 0.8 were considered moderate-to-good; those greater than 0.8 were considered excellent. For comparison purposes, effect size also was calculated with data grouped by means of GSRS, RDQ and QoLRAD.

Patients were also classified after four weeks of treatment as PASS test responders (visit 3 PASS score 0) or PASS test nonresponders (visit 3 PASS score greater than 0 ).

For the analysis, the OTE was collapsed into four different categories: no change (OTE equals $-1,0,+1$ ); small change (OTE 


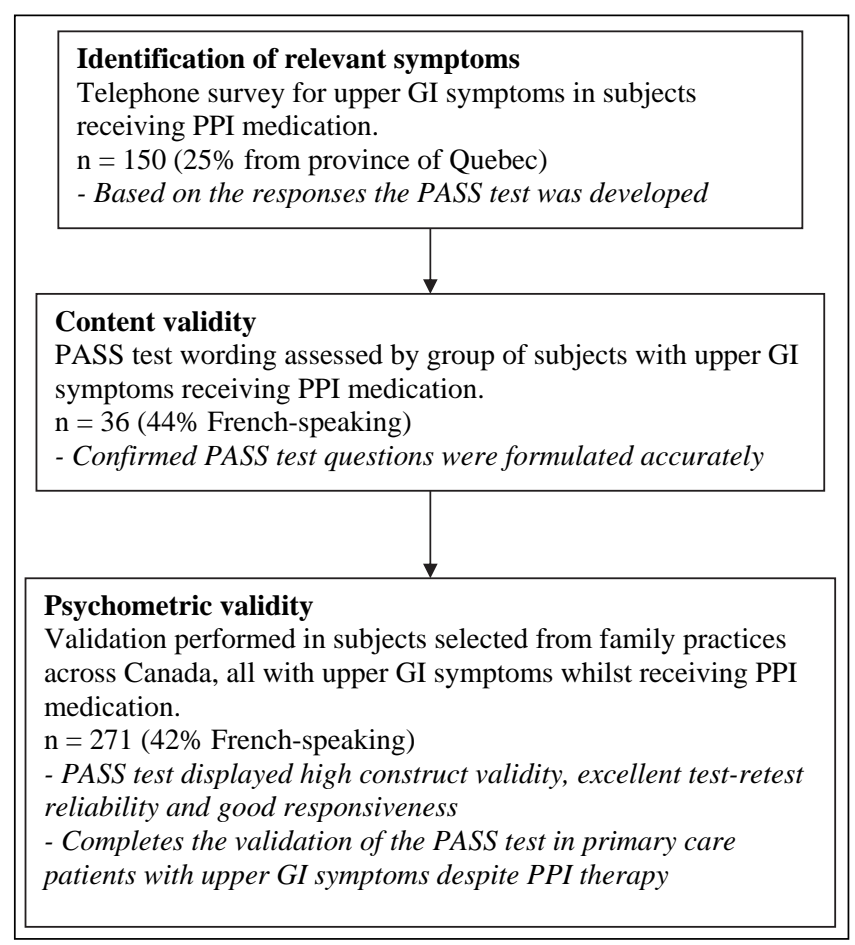

Figure 2) Overview of the process of validation for the Proton pump inhibitor (PPI) Acid Suppression Symptom (PASS) test with the accomplishments of each stage. GI Gastrointestinal

equals $-3,-2,+2,+3$ ); moderate change (OTE equals $-5,-4,+4$, $+5)$; and large change (OTE equals $-7,-6,+6,+7)(31,34)$.

The ability of the PASS test to detect clinical and statistical differences between responders and nonresponders was reported by the use of $95 \%$ CI for simple one-way analysis of variance for both the English and the French versions of the PASS test, against each of the validated instruments. CIs not crossing zero were considered statistically significant $(\mathrm{P}<0.05$ or less). No missing values were replaced.

\section{Statistical analysis}

Data analysis was performed using SAS (V8.1 2001, SAS Institute Inc, USA). Nominal data were expressed as percentages with ranges and numerical data as means with SDs.

\section{Sample size}

Statistical power analysis based on test-retest reliability and anticipated patient dropout rates indicated the need for 200 patients (100 patients each with English or French as their first language) to detect at least a moderate effect size of 0.5 , assuming a delta of 0.5 units and an SD of one unit in the PASS test. Two hundred ninety patients from 38 family physician centres across Canada were enrolled to ensure that 200 patients completed the study.

\section{RESULTS}

An overview of the validation process for the PASS test is provided in Figure 2.

\section{Initial identification of symptoms and potential PASS} questions

Analysis of the telephone survey, completed by 150 patients, indicated that $47 \%$ of patients supplemented their PPI with an over-the-counter medication. Stomach-related problems reported by these patients included sleeping (50\%), eating $(47 \%)$, work or daily activities (23\%), social and exercise activities $(17 \%$ to $18 \%)$ and hobbies $(15 \%)$. The main spontaneously reported GI symptoms were pain or heartburn, indigestion and acid taste or fluid in the mouth or throat, occurring in 65\%, 35\% and 29\% of cases, respectively. The most bothersome symptoms were heartburn (25\%) and acid reflux (22\%), followed by epigastric or stomach pain $(13 \%)$.

As a result of this survey, five items were selected for the draft PASS test (Figure 1).

\section{Content validity}

The survey was completed in English by 20 patients (mean age 61 years; four men) and in French by 16 patients (mean age 59 years; 10 men). Nineteen patients in the English group and 15 in the French group were taking a PPI one to three times a day before the study.

The main stomach symptom(s) were described as bloating, heartburn, flatulence or gas, regurgitation and discomfort by $75 \%$ (15 of 20 ) and 92\% (11 of 12) of the English- and Frenchspeaking groups, respectively. These are consistent with those listed as possible symptoms in the PASS test. The words 'stomach pain or discomfort' and 'heartburn' were well-understood by 95\% (19 of 20) of the English-speaking group and 100\% (12 of 12 ) of the French-speaking patients. Fifty per cent (10 of 20) (60\% [seven of 12] in the French group) thought that the best definition for heartburn was "a burning feeling rising from your stomach or lower chest toward your neck or a burning feeling located behind the breastbone which may or may not rise in the chest". The terms 'with sour taste', 'excessive burping or belching', nausea and 'increased abdominal bloating' were endorsed by $90 \%$ (18 of 20) of the English-speaking patients and $67 \%$ (eight of 12) of the French group. The term 'early satiety' was understood by $70 \%$ (14 of 20) of the English- and $67 \%$ (eight of 12) of the French-speaking group. To the question, "In general, does this list cover the range of symptoms that you experience?", 85\% (17 of 20) of the English-speaking patients responded 'Yes', as did 92\% (11 of 12) in the Frenchspeaking group.

The term 'stomach problems' for question 1 was considered adequate by 65\% (13 of 20) of the English- and 67\% (eight of 12) of the French-speaking patients to describe their symptoms.

\section{PSYCHOMETRIC VALIDITY}

Demographics and baseline characteristics

Overall, 158 English-speaking patients (mean age 56 years, $41 \%$ male) and 113 French-speaking patients (mean age 58 years, 31\% male) participated in this phase of the study. The educational backgrounds for the English-speaking group were college or university (36\%), high school (47\%) and elementary school (17\%); the corresponding figures for the French-speaking group were $31 \%, 53 \%$ and $16 \%$, respectively.

At baseline, all patients had GOS scores of at least 3 (of 7 possible), with a median GOS score of 4 for both the Englishand French-speaking groups. There were no significant differences in demographics between the English and French patient groups. All patients were receiving PPI therapy at baseline: omeprazole $(37 \%)$, pantoprazole (31\%), lansoprazole (16\%) and rabeprazole $(16 \%)$. Two hundred forty-nine patients of the initial 271 remained in the study for four weeks after visit 2 and 


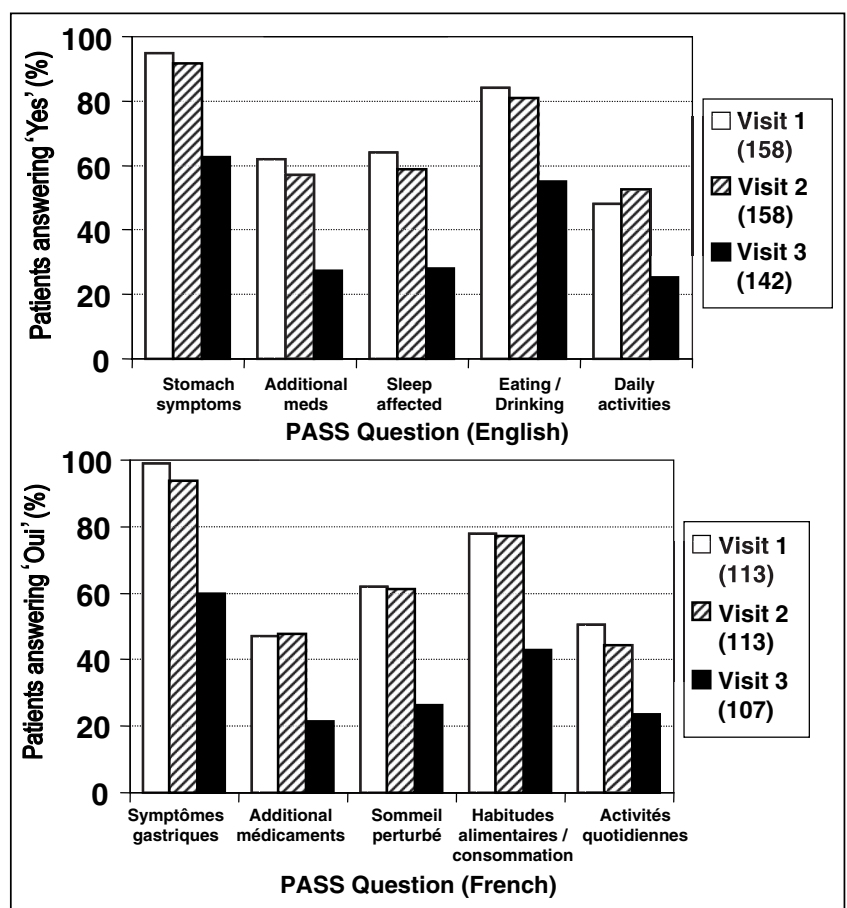

Figure 3) The percentages of patients answering 'Yes' to each question, at the three visits, for English- (upper panel) and French-speaking (lower panel) patients. Meds Medications; PASS Proton pump inhibitor Acid Suppression Symptom test

completed the follow-up assessments. Except for two patients (with a compliance rate of less than $80 \%$ ), all patients had a high compliance rate with the medication during the fourweek treatment phase.

Mean total PASS scores were 3.5 (SD 1.2) and 3.4 (SD 1.4) for visits 1 and 2, respectively, in the English group; and 3.4 (SD 1.2) and 3.3 (SD 1.3), respectively, in the French group. After the four-week treatment, at visit 3, the mean total PASS scores had fallen to 2.0 (SD 1.7) and 1.7 (SD 1.7) in the English and French groups, respectively. The proportions of patients answering 'Yes' to the individual questions were comparable at visits 1 and 2 but fell markedly by visit 3 (Figure 3).

Test-retest reliability and internal consistency

Test-retest analysis correlation coefficients were calculated for all patients in each group by comparing study results obtained at visits 1 and 2 . Test-retest coefficients were 0.76 and 0.68 for the English and French versions of PASS test, respectively, indicating good-to-excellent reliability.

Internal consistency measurement by means of $\mathrm{G}$-analysis gave results in the moderate range (between 0.50 and 0.48 ) for English and French. Assessment of internal consistency at visit 2, which was performed by comparing scores for individual items with the summed scores for the other four items, indicated a low-to-moderate correlation $(0.15$ to 0.46$)$ for all items in both languages.

\section{Construct validity}

The PASS test scores were compared with baseline scores for the comparator scales (GSRS, QoLRAD and RDQ) to evaluate construct validity (Table 2 ).

The PASS test score from visit 2 showed moderate-to-high correlation with the overall GSRS scale in both languages
TABLE 2

Correlation coefficients $(P<0.0001$ unless otherwise reported) for Proton pump inhibitor Acid Suppression Symptom (PASS) questionnaire scores compared with domain and overall scores for other scales by language and visit

\begin{tabular}{llcc}
\hline $\begin{array}{l}\text { SCALE, } \\
\text { Language }\end{array}$ & Domains & PASS total (visit 2) & PASS total (visit 3) \\
\hline $\begin{array}{c}\text { GSRS } \\
\text { English }\end{array}$ & Diarrhea & 0.36 & 0.35 \\
& Indigestion & 0.42 & 0.59 \\
& Constipation & $0.22(\mathrm{P}=0.0060)$ & 0.40 \\
& Abdominal pain & 0.56 & 0.76 \\
& Reflux & 0.40 & 0.70 \\
& GSRS overall & 0.51 & 0.74 \\
French & Diarrhea & $0.17(\mathrm{P}=0.0753)$ & $0.20(\mathrm{P}=0.0321)$ \\
& Indigestion & $0.34(\mathrm{P}=0.0002)$ & 0.51 \\
& Constipation & $0.23(\mathrm{P}=0.0158)$ & $0.29(\mathrm{P}=0.0022)$ \\
& Abdominal pain & $0.32(\mathrm{P}=0.0005)$ & 0.55 \\
& Reflux & $0.35(\mathrm{P}=0.0002)$ & 0.63 \\
& GSRS overall & 0.43 & 0.62
\end{tabular}

QoLRAD

English

Emotional distres

$-0.52$

$-0.74$

Sleep disturbance

$-0.57$

Food or drink problem $\quad-0.51$

Physical or social

$-0.49$

Vitality

French

Emotional distress

$-0.52$

Sleep disturbance

$-0.41$

Food or drink problem

$-0.50$

Physical or social

$-0.43$

$-0.38$

Vitality

$-0.31(P<0.001)$

$-0.70$

$-0.80$

$-0.71$

$-0.75$

$-0.63$

$-0.74$

$-0.63$

$-0.57$

$-0.63$

RDQ

English

Heartburn

0.32

0.56

Regurgitation

0.36

0.55

0.63

Epigastric pain

0.42

GERD

Overall RDQ

0.37

0.64

0.68

French

Heartburn

0.41

0.55

Regurgitation

$0.25(\mathrm{P}=0.0016)$

0.55

Epigastric pain

$0.30(P=0.0013)$

0.54

GERD

$0.22(P=0.0196)$

0.69

Overall RDQ

0.37

0.69

GERD Gastroesophageal reflux disease; GSRS Gastrointestinal Symptom Rating Scale; QoLRAD Quality of Life in Reflux and Dyspepsia; RDQ Reflux Disease Questionnaire

(0.51 and 0.43$)$ and moderate QoLRAD correlation (0.38 to 0.57 ) depending on the domain and language. Some domains in each scale correlated better than others with the total PASS test score. For visit 3, all correlations were higher, reflecting the treatment response. In all instances, the sign of the correlation was in the appropriate direction. However, weak-tomild correlation was found for RDQ with lower values for the French version than the English. Again for visit 3, there was a substantial increase in correlation between PASS test scores and RDQ, both for total score and all domains. There was a poor correlation between the PASS test scores and the acidindependent GSRS dimensions of constipation and diarrhea. 
TABLE 3

Effect sizes for Proton pump inhibitor Acid Suppression Symptom (PASS) test responders (PASS score $=0$ ) and PASS test nonresponders (PASS score $>0$ ) for the Gastrointestinal Symptom Rating Scale (GSRS), Quality of Life in Reflux and Dyspepsia (QoLRAD) and Reflux Disease Questionnaire (RDQ) by domain after four weeks of treatment

\begin{tabular}{|c|c|c|c|c|}
\hline \multirow[b]{2}{*}{$\begin{array}{l}\text { SCALE, } \\
\text { Domain }\end{array}$} & \multicolumn{2}{|c|}{ English } & \multicolumn{2}{|c|}{ French } \\
\hline & $\begin{array}{c}\text { Non- } \\
\text { responders }\end{array}$ & Responders & $\begin{array}{c}\text { Non- } \\
\text { responders }\end{array}$ & Responders \\
\hline \multicolumn{5}{|l|}{ GSRS } \\
\hline Diarrhea & -0.17 & -0.68 & -0.27 & -0.44 \\
\hline Indigestion & -0.45 & -0.96 & -0.69 & -1.20 \\
\hline Constipation & -0.26 & -0.55 & -0.21 & -0.71 \\
\hline Abdominal pain & -0.43 & -1.04 & -0.61 & -1.14 \\
\hline Reflux & -0.61 & -1.20 & -0.70 & -1.38 \\
\hline \multicolumn{5}{|l|}{ QoLRAD } \\
\hline Emotional distress & ss 0.50 & 0.92 & 0.51 & 1.31 \\
\hline Sleep disturbance & 0.49 & 0.93 & 0.47 & 1.27 \\
\hline $\begin{array}{l}\text { Food or drinking } \\
\text { problem }\end{array}$ & 0.69 & 1.29 & 0.62 & 1.53 \\
\hline Physical or social & 0.35 & 0.68 & 0.35 & 1.15 \\
\hline Vitality & 0.55 & 1.08 & 0.48 & 1.45 \\
\hline \multicolumn{5}{|l|}{$\mathrm{RDQ}$} \\
\hline Heartburn & -0.49 & -1.00 & -0.46 & -1.21 \\
\hline Regurgitation & -0.53 & -0.95 & -0.38 & -1.12 \\
\hline Epigastric pain & -0.41 & -0.95 & -0.53 & -1.29 \\
\hline GERD & -0.56 & -1.04 & -0.49 & -1.34 \\
\hline
\end{tabular}

GERD Gastroesophageal reflux disease

Greater symptom severity, recorded by the GOS score at baseline, was associated with higher total PASS scores (data not shown). Similar trends were observed for the other validated scales.

Responsiveness and discriminant validity

The PASS results showed that 42 (30\%) and 35 (33\%) patients in the English- and French-speaking groups, respectively, were 'PASS test responders' on a per protocol analysis; ie, they had complete resolution of their symptoms (PASS test score 0$)$ at the end of treatment.

Most of the effect sizes for individual domains of the three validated scales GSRS, RDQ and QoLRAD were moderate-togood for PASS test responders in both the English- and French-speaking groups (Table 3 ) and responders' effect sizes were, on average, two to three times higher than the effect sizes for the PASS test nonresponders.

The first PASS question provided the greatest observed response reduction $(-1.25$ and -1.68 for English and French, respectively), with other questions providing responses in the range of 0.45 to 0.85 (data not shown), comparable to the individual domain responses for all three validated scales. Despite the small number of subjects in some response classes, greater improvement was observed in those PASS test responders who had also reported a larger overall treatment effect (Figure 4). For PASS test responders, a large overall treatment effect was associated with an effect size of $-2.95(-3.67 / 1.24)$ and -3.22 $(-3.90 / 1.21)$ for the English and French groups, respectively.

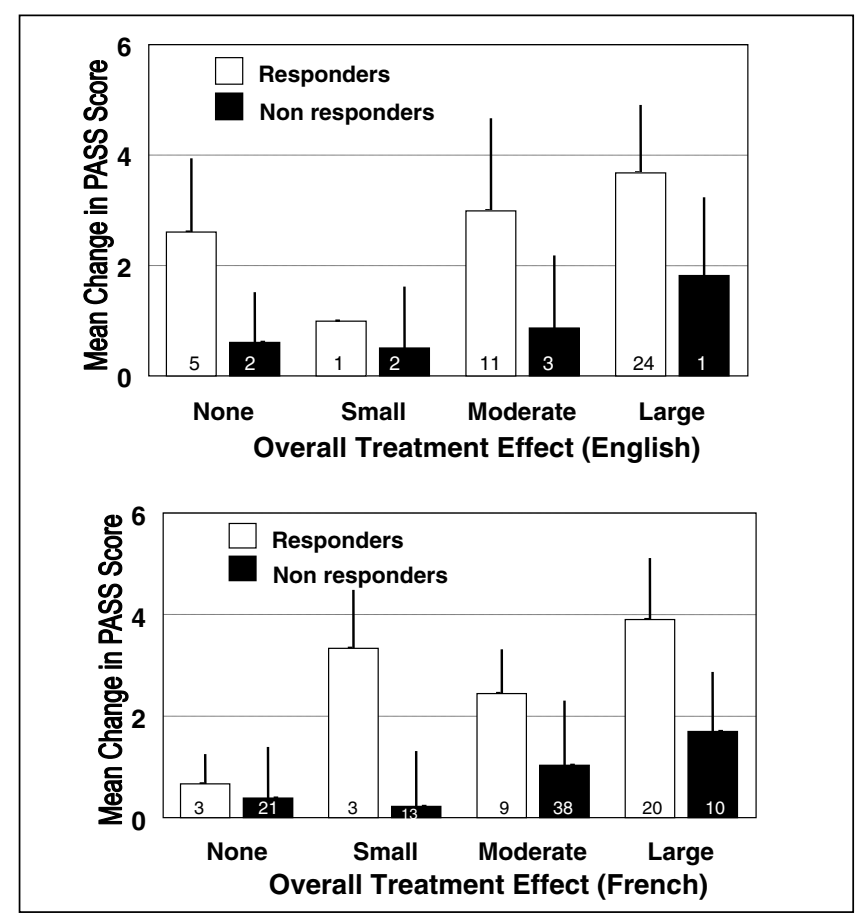

Figure 4) Mean change in Proton pump inhibitor Acid Suppression Symptom (PASS) total score (line indicates SD) for PASS test responders and nonresponders, stratified by degree of change in overall treatment effect ( $n$ in each column) after four weeks of treatment at visit 3 for both English-(upper panel) and French-speaking (lower panel) patients

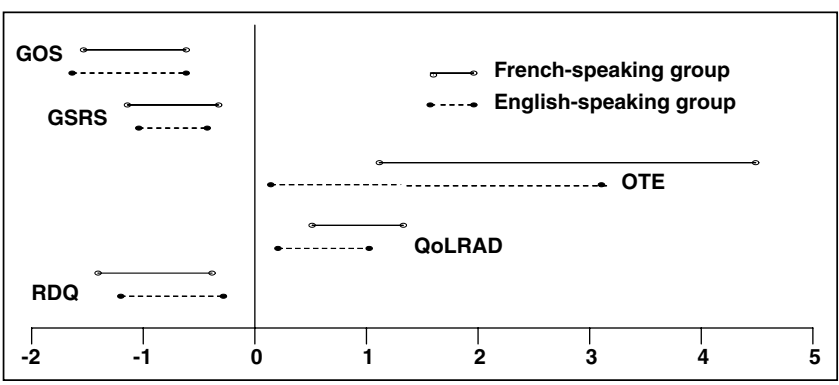

Figure 5) Difference in scores (95\% CI) between Proton pump inhibitor Acid Suppression Symptom test responders and nonresponders. The solid lines indicate responses from the French-speaking group and the dashed lines indicate responses from the English-speaking group. GOS Global Overall Symptom scale; GSRS Gastrointestinal Symptom Rating Scale; OTE Overall treatment effect; QoLRAD Quality of Life in Reflux and Dyspepsia questionnaire; RDQ Reflux Disease Questionnaire

After patients switched their PPI medication at visit 2, 54\% (77 of 142) in the English-speaking group and 69\% (74 of 107) in the French-speaking group experienced symptom relief with esomeprazole based on their GOS response. In both linguistic groups, $32 \%$ of patients had a total resolution of their symptoms at the end of four weeks.

The response to treatment, calculated as the difference between scores at baseline and after treatment for all comparator scales, was significantly greater in patients defined as PASS test responders than in PASS test nonresponders (Figure 5). All scales in the plot show that patients had an improvement 
in the severity of symptoms (scored by PASS) after using esomeprazole.

\section{Safety}

Reported adverse events were mostly mild-to-moderate and transient, and none was considered to be causally related to esomeprazole therapy.

\section{DISCUSSION}

The PASS questionnaire was developed using established methodology to address the identified need for a simple clinical tool. The concerns and therapeutic needs of patients with persistent acid-related symptoms despite ongoing PPI therapy were first documented and, based on this, a list of questions was developed to assess content validity in focus groups. Five major areas or domains of interest or concern to patients were identified; therefore, the PASS questionnaire was designed as a short five-question questionnaire. With respect to content validity, the focus group members' responses were all in the good-to-excellent range, indicating that the PASS questions were clear, relevant to their experience, easy to understand and suitable for the development of a questionnaire. Acknowledging the importance of linguistic and cultural differences in Canada, the French and English versions were developed separately, rather than by back-translation from one language to the other.

Psychometric validation of the questionnaire focused on construct validity, test-retest reliability and responsiveness in French and English populations. The construct validity data indicate that the PASS questionnaire can detect ongoing symptoms in domains of importance to patients; this is confirmed by strong correlations between the PASS scores and other validated outcome measures including the GOS score for dyspepsia symptom severity, the QoLRAD, RDQ and GSRS questionnaires and the OTE questionnaire.

The PASS questionnaire demonstrated excellent testretest reliability when comparing questionnaire scores from the baseline visit with those obtained one week later. It also demonstrated good responsiveness in detecting a significant change in health status. Because the PASS test questionnaire was designed to pose a very limited number of questions - each question intended to address an independent aspect of the patient's symptoms - there was, as expected, low internal consistency and this was confirmed by the Ganalysis.

Approximately $30 \%$ of the patients reported complete resolution of their symptoms, based on their PASS and GOS scores. Because this was an open label treatment study, one cannot conclude that esomeprazole was superior to the previous PPI therapy but the data suggest that persistent symptoms will respond to a change in PPI therapy in a substantial proportion of patients. Further, double-blind studies are needed to determine the extent to which more potent acid suppression will produce symptom resolution in patients with persistent symptoms on standard PPI therapy.

\section{SUMMARY}

The present paper presents the development and validation of a short, five-question tool to identify patients with persistent acid-related symptoms; test scores correlate well with accepted validated scales and the new, short questionnaire shows a good response to a four-week course of acid suppression therapy with a PPI. The test has good test-retest reproducibility and responsiveness.

In its current form, the PASS questionnaire allows patients to record their current symptoms easily and it facilitates communication with their physicians; the questionnaire also allows physicians to rapidly assess their patients' symptom status during PPI therapy. As such, it should help physicians to identify patients with upper GI, acid-related problems that require rescue medication or a change in acid suppression therapy, and it may also be helpful in assessing the patients' response to treatment.

In the future, the PASS questionnaire may also be developed as a simple diagnostic test, to differentiate between those patients who have symptoms that will respond to an increase in acid suppression therapy and those patients who have other, possibly functional symptoms that are not acidrelated. This test would be beneficial in clinical practice but it might also help to determine, from a payer's perspective, whether an increase in acid suppression therapy is appropriate. Finally, it may be useful to monitor symptom response in large-scale clinical trials designed to assess the effect of changing therapy for patients with persistent reflux- or acidrelated symptoms.

ACKNOWLEDGEMENTS: The authors wish to thank Dr Geoffrey Norman for his advice in the G-analysis design, Kausar Chatoo and Nafisa Ladha for assistance with the content validity study in the French subjects, and Dr Robert Jenkins for his editorial assistance. Financially supported by a grant from AstraZeneca Canada Inc.

\section{REFERENCES}

1. Veldhuyzen van Zanten SJO, Flook N, Chiba N, et al. An evidence-based approach to the management of uninvestigated dyspepsia in the era of Helicobacter pylori. CMAJ 2000;162(Suppl 12):S3-23.

2. Tougas G, Chen Y, Hwang P, Liu MM, Eggleston A. Prevalence and impact of upper gastrointestinal symptoms in the Canadian population: Findings from the DIGEST study.

Domestic/International Gastroenterology Surveillance Study. Am J Gastroenterol 1999;94:2845-54.

3. Jones RH, Lydeard SE, Hobbs FD, et al. Dyspepsia in England and Scotland. Gut 1990;31:401-5.

4. Thomson AB, Barkun AN, Armstrong D, et al. The prevalence of clinically significant endoscopic findings in primary care patients with uninvestigated dyspepsia: The Canadian Adult Dyspepsia Empiric Treatment - Prompt Endoscopy (CADET-PE) study. Aliment Pharmacol Ther 2003;17:1481-91.

5. Hurenkamp GJ, Grundmeyer HG, Bindels PJ, Tytgat GN, Van der Hulst RW. How do primary care physicians use long-term acid suppressant drugs? A population-based analysis of Dutch general practices. J Fam Practice 2002;51:241-5.

6. Ryder SD, O'Reilley S, Miller RJ, Ross J, Jacyna MR, Levi AJ. Long-term acid suppressing treatment in general practice. BMJ 1994;308:827-30.

7. Chiba N, De Gara CJ, Wilkinson JM, Hunt RH. Speed of healing and symptom relief in grade II to IV gastroesophageal reflux disease: A meta-analysis. Gastroenterology 1997;112:1798-810.

8. Van Pinxteren B, Numans ME, Bonis PA, Lau J. Short-term treatment with proton pump inhibitors, $\mathrm{H}_{2}$-receptors antagonist and prokinetics for gastro-oesophageal reflux disease-like symptoms and endoscopy negative reflux disease. Cochrane Database Syst Rev. 2001;(4):CD002095. Review

9. Ekstrom P, Carling L, Unge P, Anker-Hansen O, Sjostedt S, Sellstrom H. Lansoprazole versus omeprazole in active duodenal ulcer. A double-blind, randomized, comparative study. Scand J Gastroenterol 1995;30:210-5. 
10. McFarland RJ, Bateson MC, Green JR, et al. Omeprazole provides quicker symptom relief and duodenal ulcer healing than ranitidine. Gastroenterology 1990;98:278-83.

11. Veldhuyzen van Zanten SJO, Chiba N, Armstrong D, et al. A double-blind, randomised controlled trial comparing omeprazole (OME), ranitidine (RAN), cisapride (CIS), and placebo (PLA) in 512 Helicobacter pylori $(\mathrm{Hp})$ negative primary care patients with uninvestigated dyspepsia (UD) - the CADET HN study. Can J Gastroenterol 2002;16(Suppl A):A5. (Abst)

12. Talley NJ. Dyspepsia: Management guidelines for the millennium. Gut 2002;50(Suppl 4):72-8.

13. Quartero AO, Numans ME, Post MW, de Melker RA, de Wit NJ. One-year prognosis of primary care dyspepsia: Predictive value of symptom pattern, Helicobacter pylori and GP management. Eur J Gastroenterol Hepatol 2002;14:55-60.

14. Meineche-Schmidt V, Jorgenson T. 'Alarm symptoms' in patients with dyspepsia: A three-year prospective study from general practice. Scand J Gastroenterol 2002;37:999-1007.

15. Jacobson BC, Ferris TG, Shea TL, Mahlis EM, Lee TH, Wang TC. Who is using chronic acid suppression therapy and why? Am J Gastroenterol 2003;98:51-8.

16. Abu Farsakh N. Symptomatic and endoscopic outcome of heartburn 3-4.5 years after starting lansoprazole therapy: A prospective study of 142 patients. J Gastroenterol 2003;38:1042-8.

17. Junghard $O$, Carlsson R, Lind T. Sufficient control of heartburn in endoscopy-negative gastro-oesophageal reflux disease trials. Scand J Gastroenterol 2003;38:1197-9.

18. Crawley J, Frank L, Joshua-Gotlib S, Flynn J, Frank S, Wiklund I. Measuring change in quality of life in response to Helicobacter pylori eradication in peptic ulcer disease - The QOLRAD. Dig Dis Sci 2001;46:571-80.

19. Jones R, Bytzer P. Review article: Acid suppression in the management of gastro-oesophageal reflux disease - an appraisal of treatment options in primary care. Aliment Pharmacol Ther 2001;15:765-72.

20. Jones R, Armstrong D, Malfertheiner P, Ducrotte P, Colin R. A multinational survey of activities of daily living and GERD in clinical practice: Is prescription therapy adequate? Gastroenterology 2003;124(Suppl 1):A505. (Abst)

21. Fallone CA, Guyatt GH, Armstrong D, et al. Do physicians correctly assess patient symptom severity in gastro-oesophageal reflux disease? Aliment Pharmacol Ther 2004;20:1161-9.

22. Carlsson R, Dent J, Bolling-Sternevald E, et al. The usefulness of a structured questionnaire in the assessment of symptomatic gastroesophageal reflux disease. Scand J Gastroenterol 1998;33:1023-9.

23. Shaw MJ, Talley NJ, Beebe TJ, et al. Initial validation of a diagnostic questionnaire for gastroesophageal reflux disease. Am J Gastroenterol 2001;96:52-7.

24. Veldhuyen Van Zanten SJ, Chiba N, Armstrong D, et al. The validation of the Global Overall Symptom (GOS) score - a 7-point Likert scale for the measurement of dyspepsia symptoms in clinical trials. Can J Gastroenterol 2004;18(Suppl A):A141. (Abst)

25. Rohss K, Lind T, Wilder-Smith C. Esomeprazole $40 \mathrm{mg}$ provides more effective intragastric acid control than lansoprazole $30 \mathrm{mg}$, omeprazole $20 \mathrm{mg}$, pantoprazole $40 \mathrm{mg}$ and rabeprazole $20 \mathrm{mg}$ in patients with gastro-oesophageal reflux symptoms. Eur J Clin Pharmacol 2004:60:531-9.

26. Vakil N, Fennerty MB. Direct comparative trials of the efficacy of proton pump inhibitors in the management of gastro-oesophageal reflux disease and peptic ulcer disease. Aliment Pharmacol Ther 2003;18:559-68.

27. Dimenas E, Glise H, Hallerback B, Hernqvist H, Svedlund J, Wiklund I. Well-being and gastrointestinal symptoms among patients referred to endoscopy owing to suspected duodenal ulcer. Scand J Gastroenterol 1995;30:1046-52.

28. Glise G, Wiklund I. Measurement of the impact of heartburn and dyspepsia on quality of life. Aliment Pharmacol Ther 1997;11 (Suppl 2):73-7.

29. Wiklund IK, Junghard O, Grace E, et al. Quality of life in reflux and dyspepsia patients. Psychometric documentation of a new diseasespecific questionnaire (QOLRAD). Eur J Surg Suppl 1998;583:41-9.

30. Veldhuyzen van Zanten SJO, Wiklund I, White R, et al. Validation of the reflux disease questionnaire (RDQ), a new symptom scale for use in patients with upper gastrointestinal symptoms. Gastroenterology 2004;126(Suppl 2):A438. (Abst)

31. Jaeschke R, Singer J, Guyatt GH. Measurement of health status. Ascertaining the minimally clinically important diference. Control Clin Trials 1989;10:407-15.

32. Streiner LD, Norman RG. Health Measurement Scales: A Practical Guide to their Development and Use. Oxford: Oxford University Press, 1995.

33. Juniper EF, Guyatt GH, Willan A, Griffith LE. Determining a minimal important change in a disease-specific quality of life questionnaire. J Clin Epidemiol 1994;47:81-7.

34. Talley NJ, Fullerton S, Junghard O, Wiklund I. Quality of life in patients with endoscopy-negative heartburn: Reliability and sensitivity of disease-specific instruments. Am J Gastroenterol 2001;96:1998-2004. 


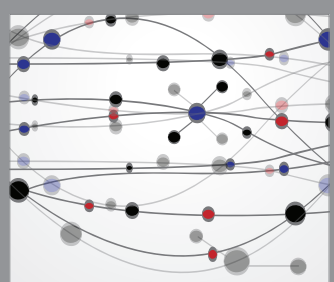

The Scientific World Journal
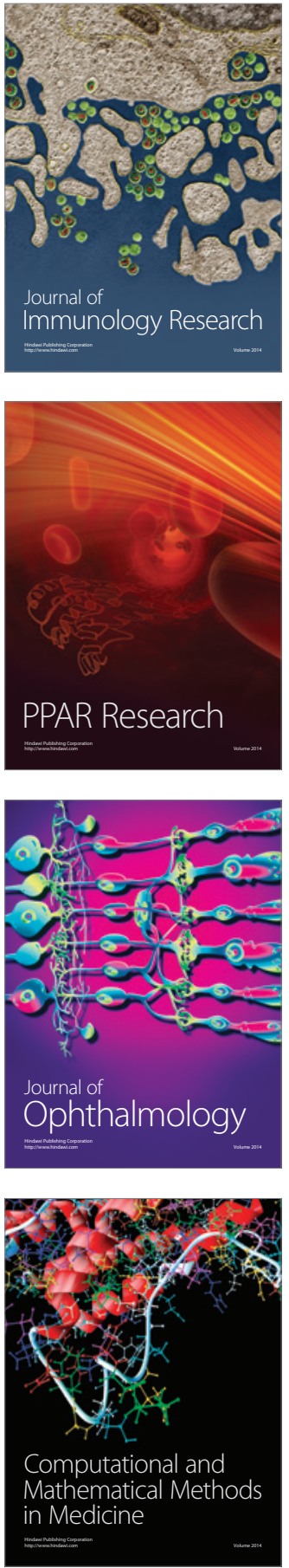

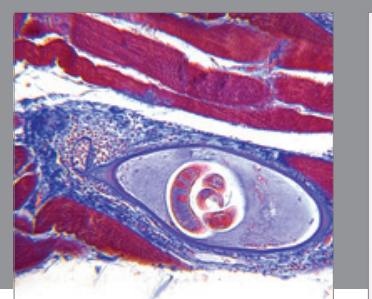

Gastroenterology Research and Practice

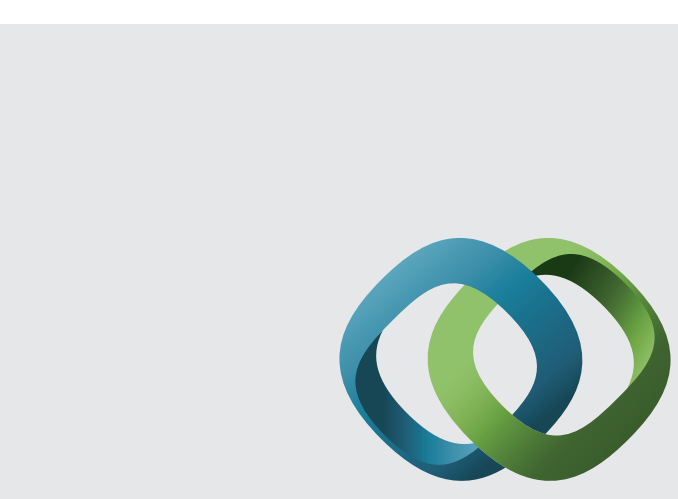

\section{Hindawi}

Submit your manuscripts at

http://www.hindawi.com
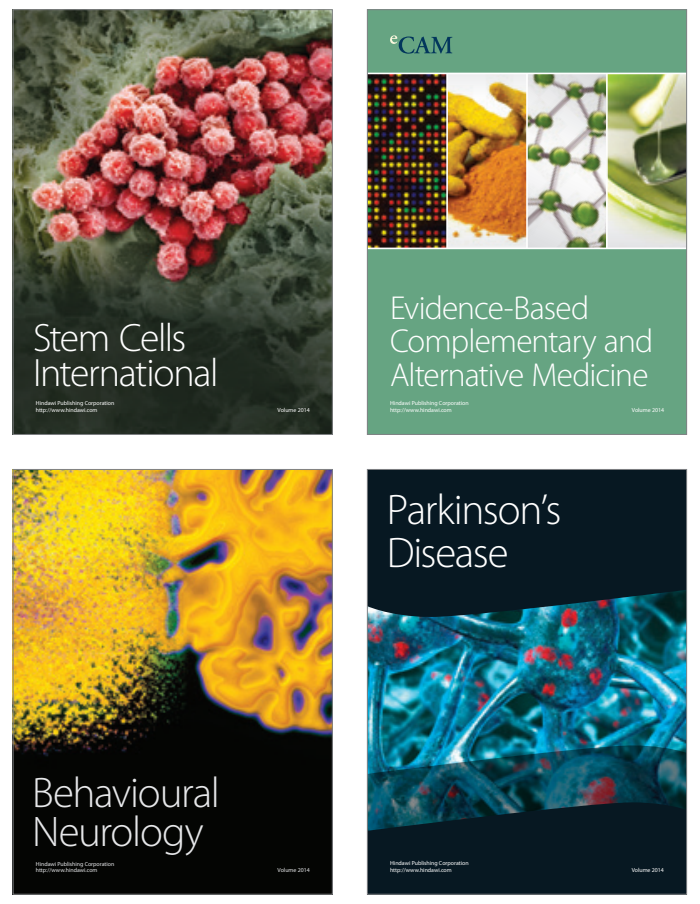
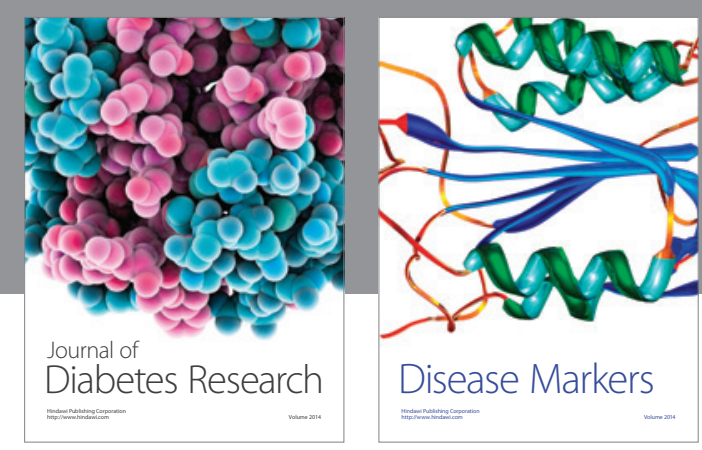

Disease Markers
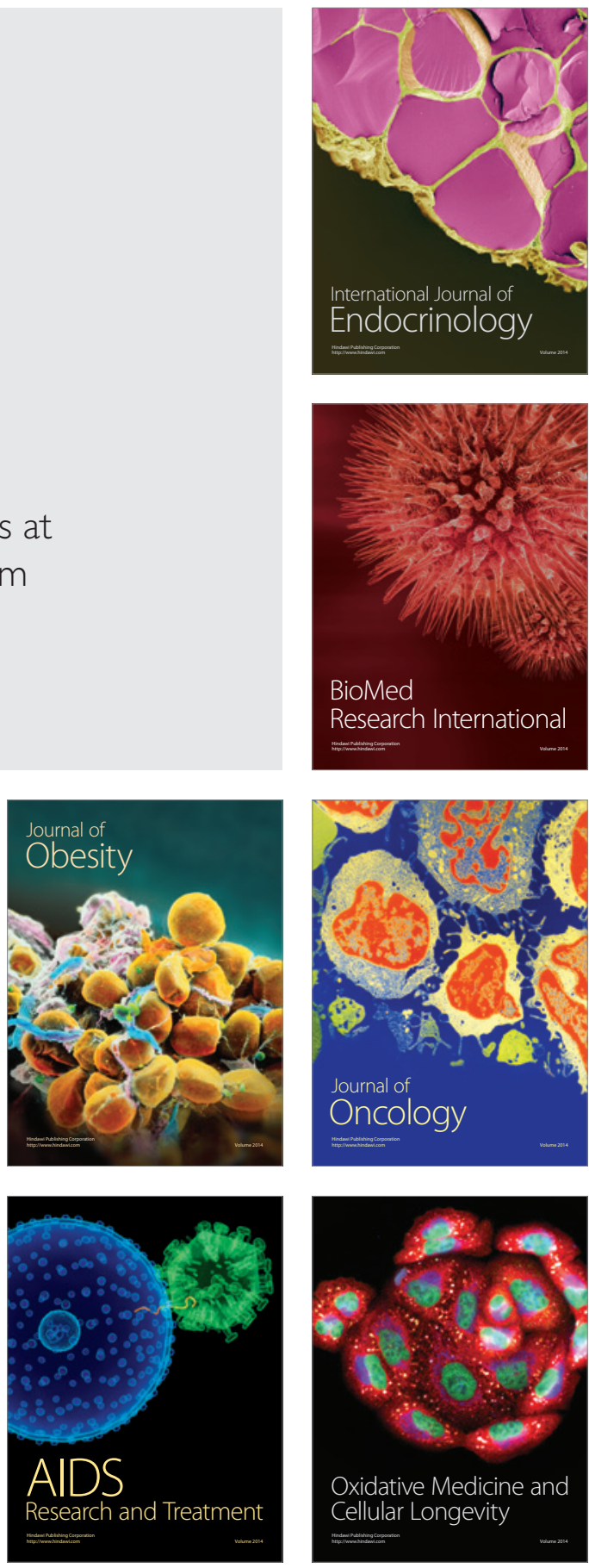